Prepared in cooperation with the

North Coast and Cascades Network, National Park Service

\title{
Prairie Monitoring Protocol Development: North Coast and Cascades Network
}

Open-File Report 2008-1168 



\section{Prairie Monitoring Protocol Development: North Coast and Cascades Network}

By Allen McCoy and Craig Dalby, Pacific West Region GIS Group, Seattle, Washington

Prepared in cooperation with the

North Coast and Cascades Network, National Park Service

Open-File Report 2008-1168

U.S. Department of the Interior

U.S. Geological Survey 


\section{U.S. Department of the Interior \\ KEN SALAZAR, Secretary}

\section{U.S. Geological Survey \\ Suzette M. Kimball, Acting Director}

U.S. Geological Survey, Reston, Virginia: 2009

For more information on the USGS - the Federal source for science about the Earth, its natural and living resources, natural hazards, and the environment, visit http://www.usgs.gov or call 1-888-ASK-USGS.

For an overview of USGS information products, including maps, imagery, and publications, visit http://www.usgs.gov/pubprod

To order this and other USGS information products, visit http://store.usgs.gov

Suggested citation:

McCoy, A., and Dalby, C., 2009, Prairie monitoring protocol development: North Coast and Cascades Network: U.S. Geological Survey Open-File Report 2008-1168, 10 p.

Any use of trade, product, or firm names is for descriptive purposes only and does not imply endorsement by the U.S. Government.

Although this report is in the public domain, permission must be secured from the individual copyright owners to reproduce any copyrighted material contained within this report. 


\section{Contents}

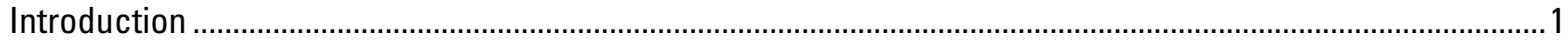

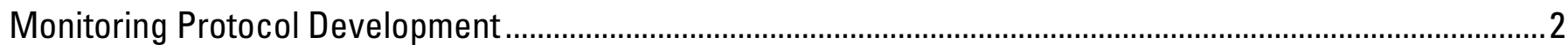

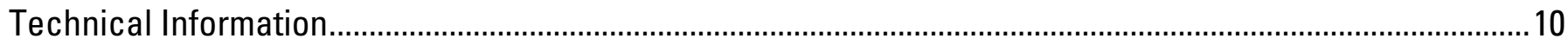

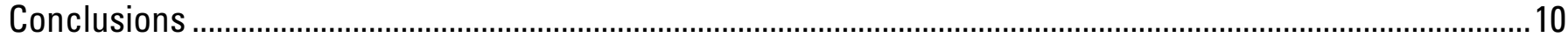

\section{Figures}

Figure 1. American Camp land cover classified into seven land-cover types, 1997.................................... 4

Figure 2. American Camp land cover classified into seven land-cover types, 2007 ....................................4

Figure 3. American Camp land-cover change, 1997-2007 ............................................................................5

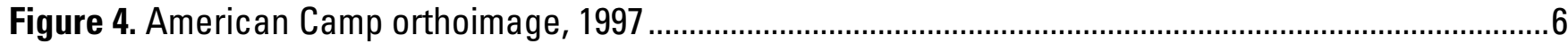

Figure 5. English Camp land cover classified into seven land-cover types, 1997 ......................................8

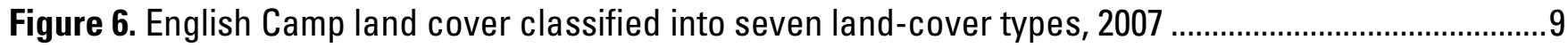

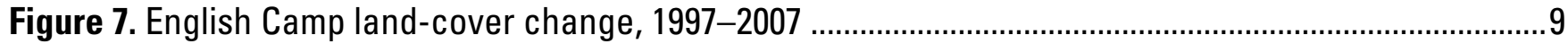

\section{Tables}

Table 1. Acreages of the seven land-cover categories for American Camp from 1997 and 2007

orthoimagery 3

Table 2. Land-cover change for American Camp, 1997-2007

Table 3. Acreages of seven land-cover categories for English Camp from 1997 and 2007 orthoimagery....7

Table 4. Land-cover change for English Camp, 1997-2007. 


\section{Conversion Factors}

\section{SI to Inch/Pound}

\begin{tabular}{lll}
\hline \multicolumn{1}{c}{ Multiply } & By & \multicolumn{1}{c}{ To obtain } \\
\hline centimeter $(\mathrm{cm})$ & 0.3937 & inch (in.) \\
meter $(\mathrm{m})$ & 3.281 & foot $(\mathrm{ft})$ \\
\hline
\end{tabular}

Inch/Pound to SI

\begin{tabular}{lccc}
\hline & Multiply & By & To obtain \\
\hline acres & 0.4047 & hectares & \\
\hline
\end{tabular}




\title{
Prairie Monitoring Protocol Development: North Coast and Cascades Network
}

\author{
By Allen McCoy ${ }^{1}$ and Craig Dalby ${ }^{1}$
}

\section{Introduction}

The purpose of the project was to conduct research that will guide development of a standard approach to monitoring several components of prairies within the North Coast and Cascades Network (NCCN) parks. Prairies are an important element of the natural environment at many parks, including San Juan Island National Historical Park (NHP) and Ebey's Landing National Historical Reserve (NHR). Forests have been encroaching on these prairies for many years, and so monitoring of the prairies is an important resource issue.

This project specifically focused on San Juan Island NHP. Prairies at Ebey's Landing NHR will be monitored in the future, but that park was not mapped as part of this prototype project.

In the interest of efficiency, the Network decided to investigate two main issues before launching a full protocol development effort: (1) the imagery requirements for monitoring prairie components, and (2) the effectiveness of software to assist in extracting features from the imagery.

Several components of prairie monitoring were initially identified as being easily tracked using aerial imagery. These components included prairie/forest edge, broad prairie composition (for example, shrubs, scattered trees), and internal exclusions (for example, shrubs, bare ground). In addition, we believed that it might be possible to distinguish different grasses in the prairies if the imagery were of high enough resolution.

Although the areas in question at San Juan Island NHP are small enough that mapping on the ground with GPS (Global Positioning System) would be feasible, other applications could benefit from aerial image acquisition on a regular, recurring basis and thereby make the investment in aerial imagery worthwhile. The additional expense of orthorectifying the imagery also was determined to be costeffective.

\footnotetext{
${ }^{1}$ Pacific West Region GIS Group, Seattle, Washington
} 


\section{Monitoring Protocol Development}

Specifications for imagery adequate for mapping of prairie edges, composition, and exclusions called for $15-\mathrm{cm}$ (approximately $0.5 \mathrm{ft}$ ) resolution with a horizontal accuracy of approximately $1 \mathrm{~m}$, and natural color or color infrared (CIR) images. Natural color imagery rather than CIR was selected because it will be useful for a wider variety of applications at the park.

After testing various rules of inclusion/exclusion for manually digitizing features in early 2006 using 1997 images of San Juan Island NHP, we proceeded in fall 2006 with testing an automated method for extracting landscape classes from the imagery using an ArcGIS ${ }^{\circledR}$ extension called Feature Analyst $^{\circledR}$ (Visual Learning Systems, Inc.). Feature Analyst ${ }^{\circledR}$ extracted about 80-90 percent of the features desired when used with properly defined training sets. This level of success enables us to suggest using the extension, or a similar one, in a semi-automated digitizing process for monitoring prairies.

The transition from mostly manual digitizing to a semi-automated digitizing process also allowed us to eliminate one of our initial land-cover classes: mixed forest and prairie. Because the feature extraction software was able to digitize so much detail far faster than we could have manually digitized it, we were able to capture virtually every forest grove and even a majority of individual trees.

New aerial orthoimagery was originally planned to be acquired in early summer 2006, but contracting difficulties precluded this from happening. As a result, the aerial imagery acquisition occurred in June 2007. The contractor provided an initial delivery in July 2007 and a supplemental delivery in September 2007. These data were reviewed for accuracy and found acceptable.

Several tests were run with Feature Analyst ${ }^{\circledR}$ on the new 2007 imagery. After multiple adjustments to the training sets, a very satisfactory data layer for the forest cover was achieved, which required only a few hours of clean up. The principal factor in obtaining acceptable results from the program was digitizing training polygons throughout the entire image. Variations in color and texture from place to place, even for a single land-cover type, made it absolutely essential to include samples from one end of the park to the other.

After experiments with defining multiple cover types in a single run of Feature Analyst ${ }^{\circledR}$ proved $^{\circ}$ disappointing, the program was used to delineate only forest areas in a single run. The land-cover categories, water, roads, bare earth, and buildings were small enough in size to manually digitize, and the prairie category was simply defined as all leftover polygons.

One disappointing result became apparent in the process of digitizing the land cover at American Camp. We were unable to discern with much accuracy all shrubs from grasses in the prairie zone when digitizing land cover. In many cases, it was quite clear that an area was covered with shrubs, we presume mostly Rosa nutkana, but in many other instances it was just not possible to make a reliable identification. We therefore decided not to make the distinction and to leave all shrubs in the prairie category. Subsequent work will examine the effectiveness of using CIR to delineate shrubs in the prairie areas. Lidar data were not available to help distinguish between taller and shorter vegetation. 
Most of the other land-cover classes were fairly homogeneous. However, several classes of land cover were grouped into the bare earth category. Areas of driftwood, beaches, sand dunes, and rock were put into this single class.

Acreages of the seven land-cover categories for American Camp, compiled from the 1997 and 2007 orthoimagery, are shown in table 1. Table 2 shows the acreages that remained as prairie or forest land-cover types, as well as the acreage that changed from one type to the other from 1997 to 2007.

Table 1. Acreages of the seven land-cover categories for American

Camp from 1997 and 2007 orthoimagery.

\begin{tabular}{lcc}
\hline $\begin{array}{c}\text { American Camp } \\
\text { land-cover category }\end{array}$ & $\begin{array}{c}\mathbf{1 9 9 7} \\
\text { acreage }\end{array}$ & $\begin{array}{c}\mathbf{2 0 0 7} \\
\text { acreage }\end{array}$ \\
\hline Bare Earth & 85.1 & 85.4 \\
Buildings & 0.1 & 0.1 \\
Forest & 361.6 & 435.8 \\
Managed grassland & 5.3 & 5.2 \\
Prairie & 771.3 & 695.7 \\
Roads & 16.7 & 16.7 \\
Water & 9.0 & 10.1 \\
\hline
\end{tabular}

Table 2. Land-cover change for American Camp, 1997-2007.

\begin{tabular}{ccc}
\hline Units, in acres & Prairie in 2007 & Forest in 2007 \\
\hline Prairie in 1997 & 675.8 & 77.4 \\
Forest in 1997 & 4.1 & 357.3 \\
\hline
\end{tabular}


Figures 1 and 2 show the results of the land-cover classification at American Camp for 1997 and 2007, respectively.

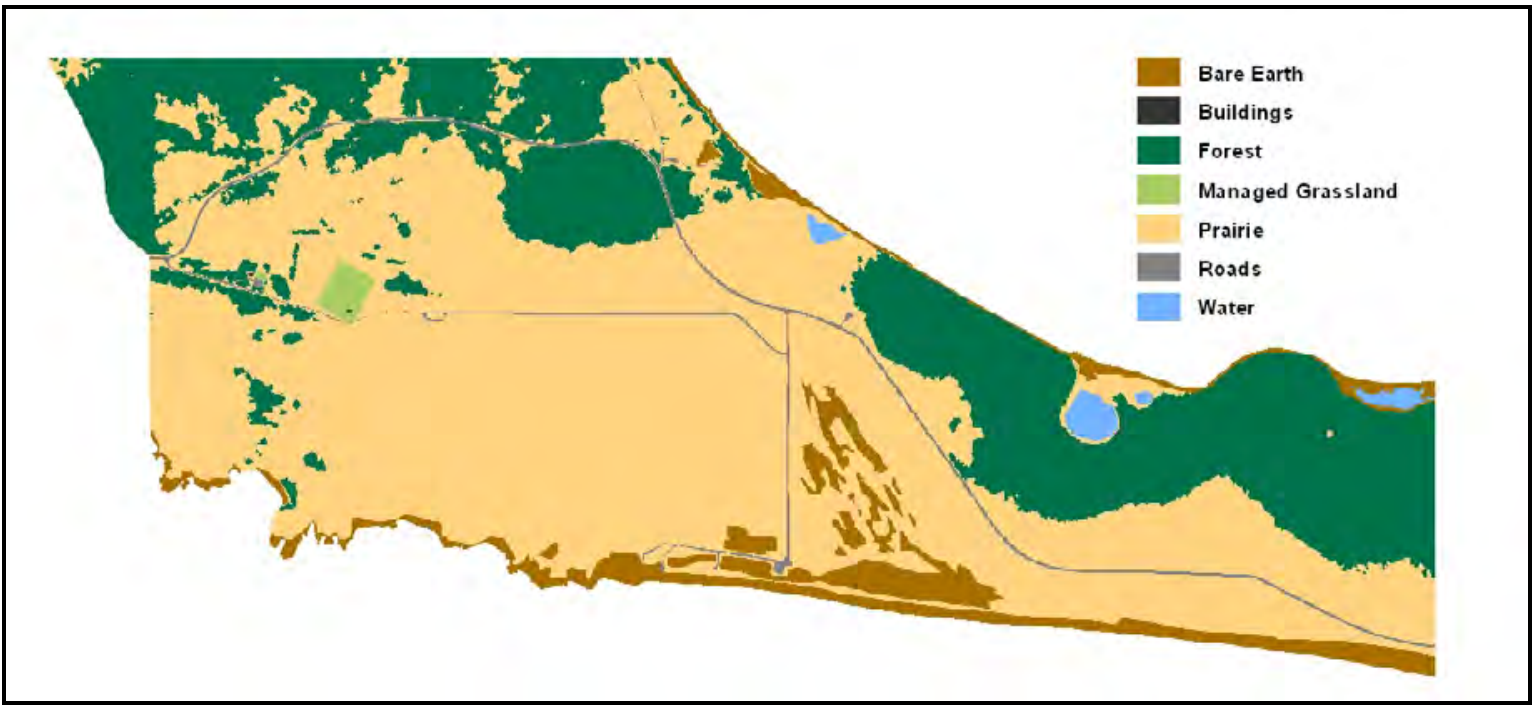

Figure 1. American Camp land cover classified into seven land-cover types, 1997.

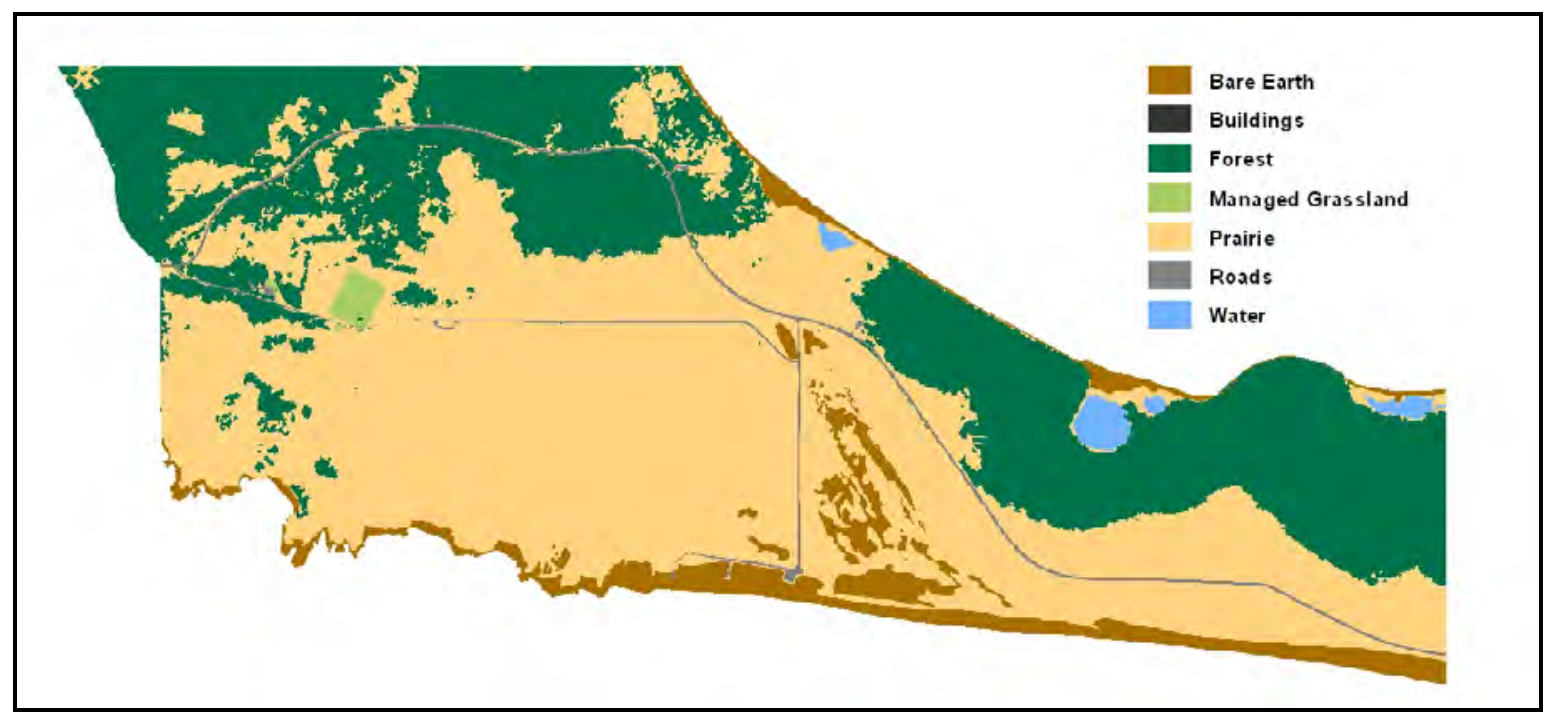

Figure 2. American Camp land cover classified into seven land-cover types, 2007. 
The most obvious change in land cover of American Camp since 1997 has been the reduction of prairie by more than 75 acres, coupled with the growth of forest by nearly the exact same amount. This is not a coincidence, as even a cursory examination of the spatial data shows (fig. 3). In 2007, the forest at American Camp, especially in the northwest corner of the park, has encroached substantially on what 10 years ago was prairie. Figure 3 depicts the forest and prairie land-cover classes, and highlights in bright green the substantial area that changed from prairie to forest.

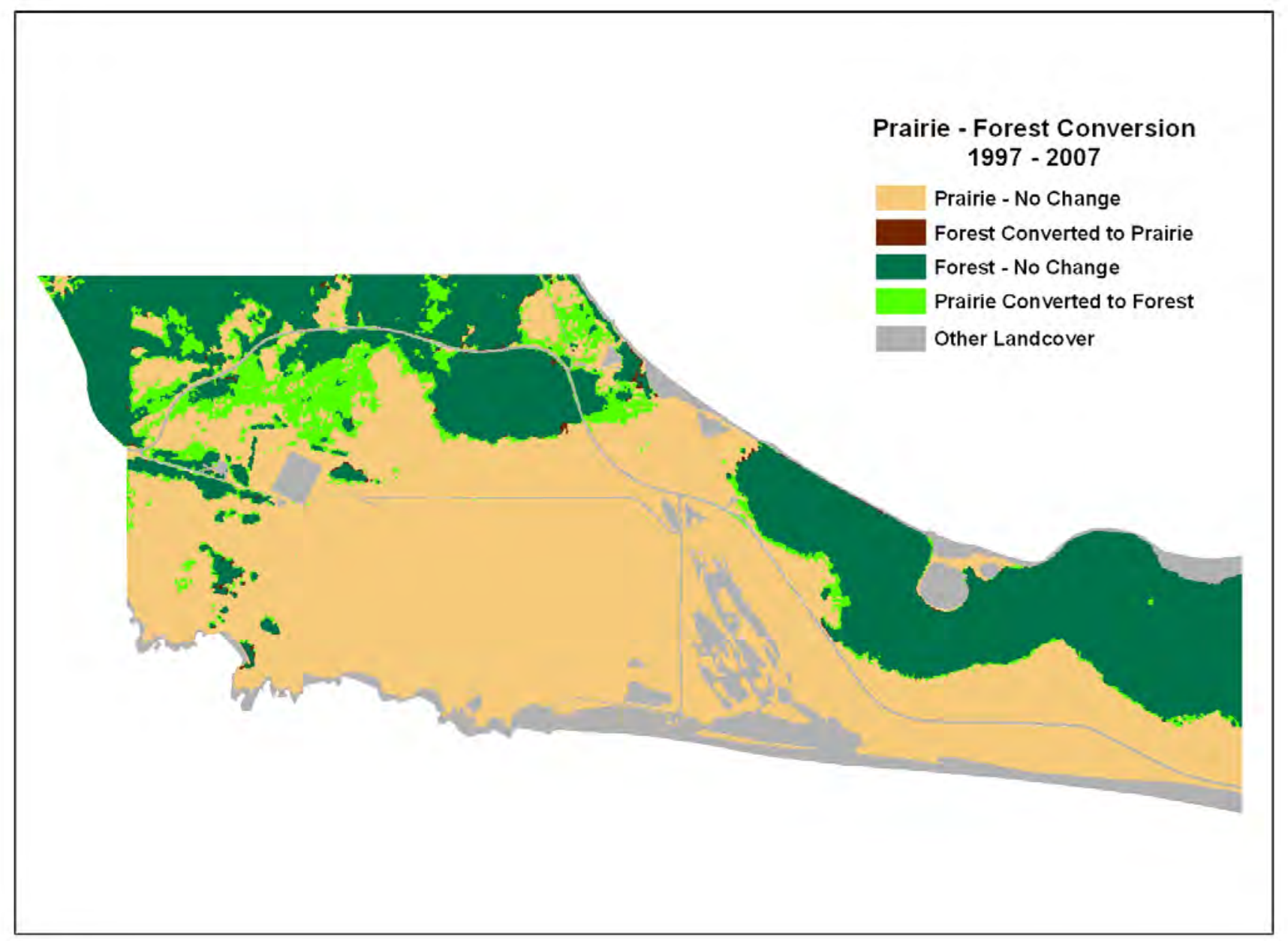

Figure 3. American Camp land-cover change, 1997-2007. 
An initial delivery of land-cover data for American Camp was made to the North Coast and Cascades Network in November 2007. However, a problem became apparent after the data were delivered: several areas that were forest zones in 1997 apparently had been converted to prairie in 2007. A subsequent investigation determined that in most instances the cause for this change was misinterpretation of the 1997 imagery. This, in turn, was largely due to the timing of the 1997 imagery, which was flown in September; some shrubs appeared to be trees as a result of the longer shadows that were cast at that time of year. A sample shrub area from the 1997 imagery (fig. 4), which was originally misclassified as forest, is enclosed with a yellow polygon, and three trees among the shrubs are noted with yellow points. Note the shadow along the northern edge of the shrubs, which makes them look much like trees. The 2007 imagery was flown in June making it easier to distinguish the short vegetation from the tree cover. These errors were corrected by manually re-digitizing the polygons.

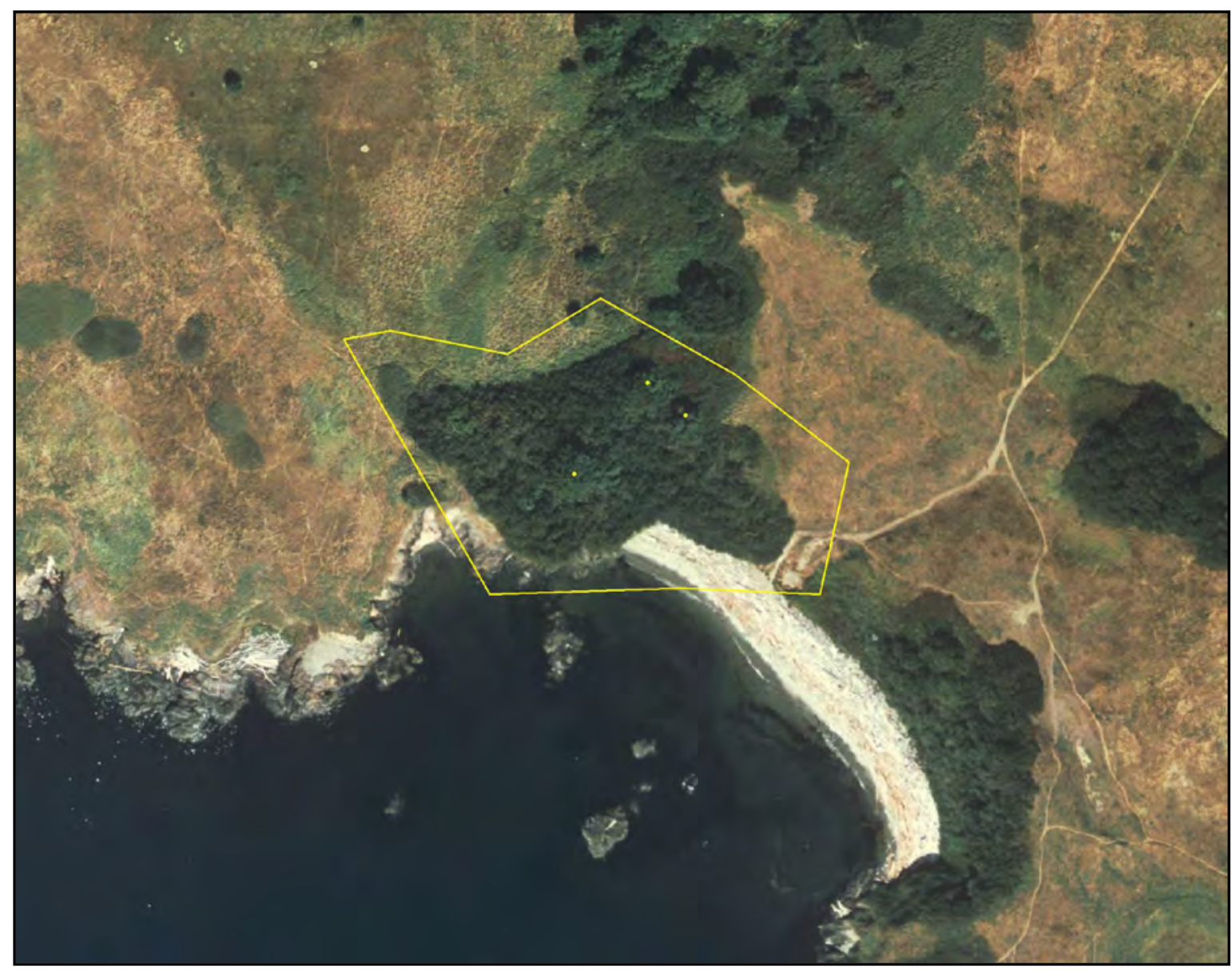

Figure 4. American Camp orthoimage, 1997. Dark green area surrounded by the yellow polygon was originally misclassified as forest as a result of the longer shadows cast at the time of year the imagery was flown. 
To complete the project, we turned our attention to English Camp where our experience changed our view somewhat as to the most effective method of using the Feature Analyst ${ }^{\oplus}$ software. At American Camp, all forested areas appeared fairly homogeneous in the orthoimagery. However, this was not the case at English Camp. Because of the low altitude at which the imagery was flown to obtain high resolution, there was pronounced "tree lean," which can arise from the apparent flattening of vertical objects in a radial pattern away from the center of each individual image. Where adjacent images were merged to form a mosaic, there was a noticeable seam in the final orthoimage. Such noticeable seams did not occur in the orthoimages for American Camp even though the amount of forested area was smaller. Furthermore, English Camp has a larger mix of broadleaf and needleleaf forest as compared to American Camp, where almost all trees are conifers. Therefore, processing with Feature Analyst ${ }^{\oplus}$ produced much better results by stratifying the forest class "training"-areas into several subgroups, each of which was more homogeneous than the forest as a whole, and then combining the results into a single category. The final acreages for all seven categories are shown in table 3.

Overall, English Camp showed only a small trend toward conversion of prairie to forest with an increase of 1.8 acres of forest and a decrease of 2.0 acres of prairie. However, the summary statistics are somewhat misleading, in part because of management interventions in the process. Several trees are known to have been removed from the south side of Young Hill after the 1997 imagery was taken, and, as a result, these previous forest areas were recorded as prairie in the 2007 imagery. Table 4 shows that there was actually a sizeable change from prairie to forest ( 15.2 acres) and forest to prairie (13.9 acres) at English Camp, which is not obvious in the summary statistics.

Table 3. Acreages of seven land-cover categories for English Camp from 1997 and 2007 orthoimagery.

\begin{tabular}{lrc}
\hline $\begin{array}{c}\text { English Camp } \\
\text { Land-Cover Category }\end{array}$ & 1997 Acreage & 2007 Acreage \\
\hline Bare Earth & 1.2 & 1.0 \\
Buildings & 0.2 & 0.2 \\
Forest & 428.6 & 430.4 \\
Prairie & 65.9 & 63.9 \\
Managed Grassland & 7.3 & 8.3 \\
Roads & 3.6 & 3.5 \\
Water & 0.4 & 0 \\
\hline
\end{tabular}

Table 4. Land-cover change for English Camp, 1997-2007.

\begin{tabular}{ccc}
\hline (Units in Acres) & Prairie in 2007 & Forest in 2007 \\
\hline Prairie in 1997 & 46.0 & 15.2 \\
Forest in 1997 & 13.9 & 414.0 \\
\hline
\end{tabular}


A geographic breakdown of the forest-prairie conversion polygons revealed that in the Young Hill area (the southeastern part of the camp), 6.5 acres converted from prairie to forest while 12.7 acres converted from forest to prairie. Elsewhere in English Camp, outside the Young Hill area, 8.7 acres converted from prairie to forest, while only 1.2 acres were recorded as converting from forest to prairie. This last figure may be due to several factors, including management activity, windthrow, and simple inherent inaccuracies in digitizing the forest edge, sometimes due to the previously mentioned "tree lean" issue.

The apparent loss of water from 1997 to 2007 was entirely due to different tidal phases when the imagery was taken. The tide was higher in the 1997 imagery than in the 2007 imagery.

Figures 5 and 6 show the results of the land-cover classification at English Camp for 1997 and 2007, respectively. Figure 7 shows the prairie and forest land-cover types for English Camp, and the areas that changed between the two classes.

In November 2007, we attempted to determine whether imagery other than natural color images would allow us to separate out shrubs from grasses in the prairies. We obtained color infrared imagery of the park from the Washington Department of Natural Resources. Our inspection and testing of the images led us to conclude that compiling data on the locations of shrubs within prairies at San Juan Island NHP, in particular American Camp, would not be any easier using color infrared imagery than with natural color imagery. There are few clues other than tone for distinguishing shrubs and grasses, and there is such fine gradation of reds to pinks in the various vegetated areas within the prairies that choosing a "break point" between the two classes would be largely arbitrary.

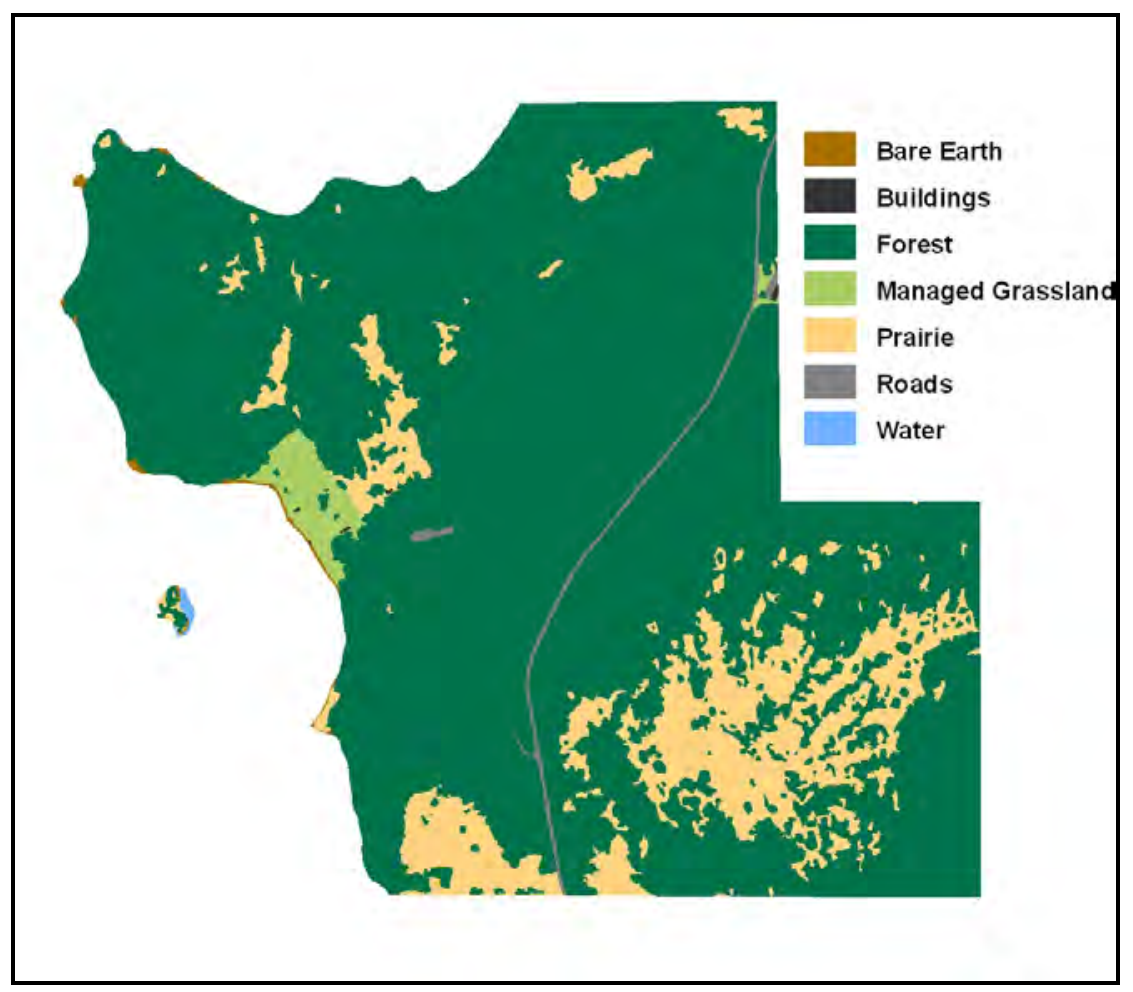

Figure 5. English Camp land cover classified into seven land-cover types, 1997. 


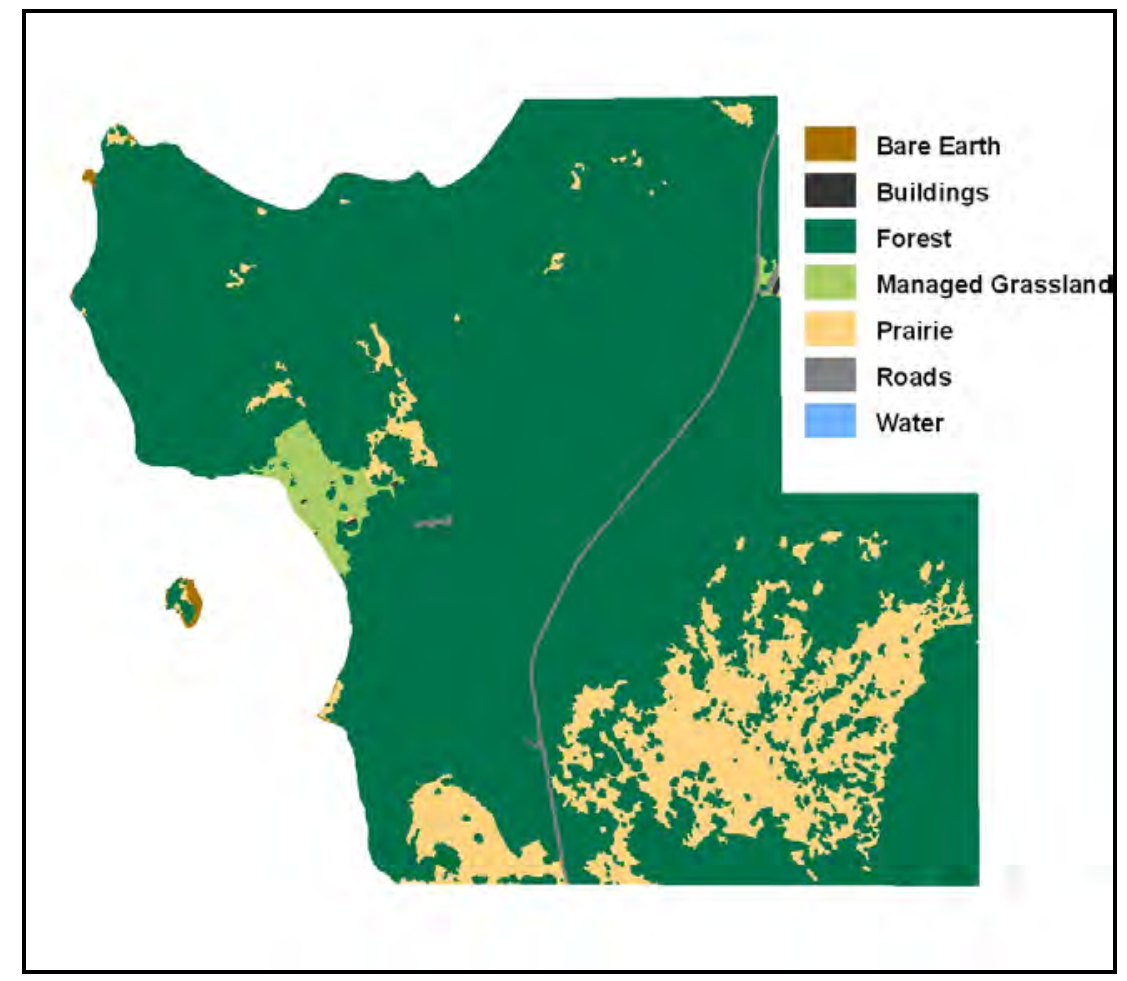

Figure 6. English Camp land cover classified into seven land-cover types, 2007.

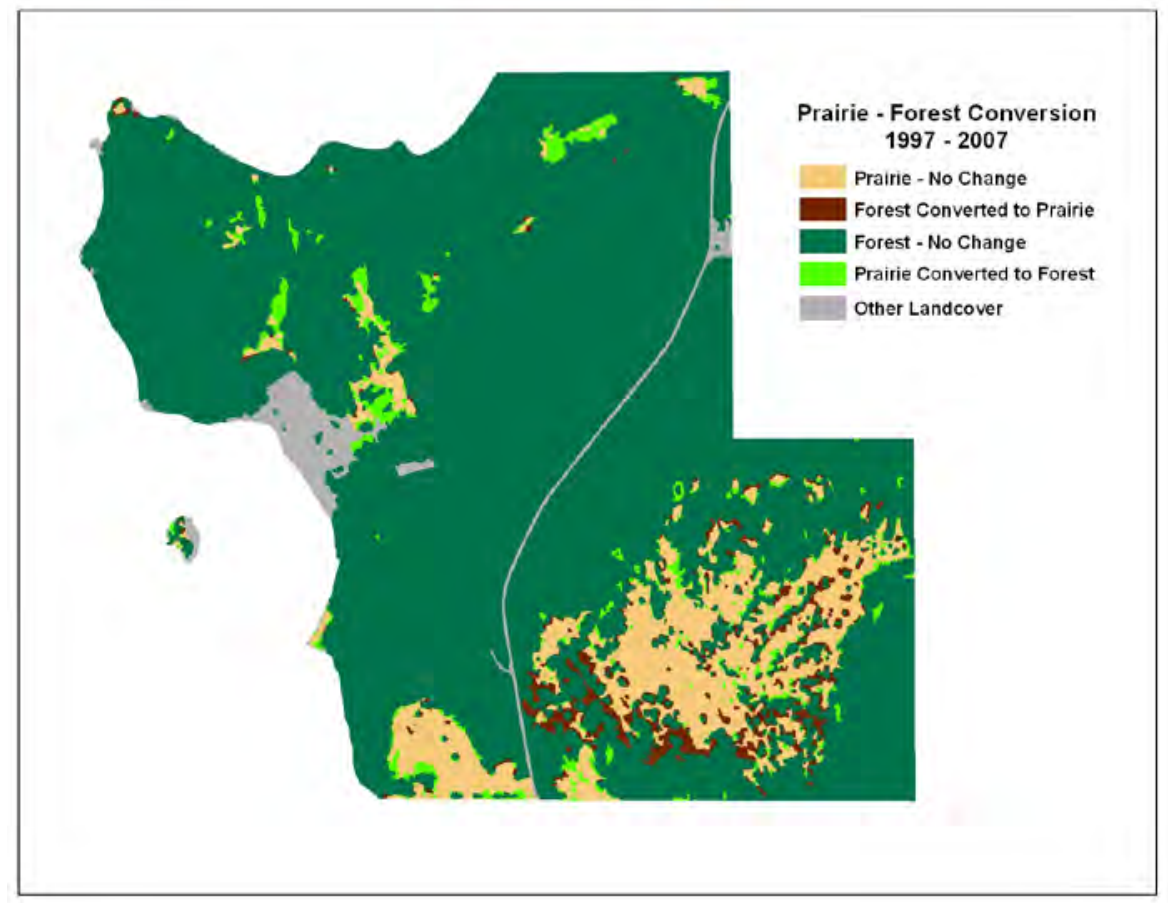

Figure 7. English Camp land-cover change, 1997-2007. 


\section{Technical Information}

The processing in this project was done using ArcGIS (ArcInfo) 9.2 from Environmental Systems Research Institute, Inc. of Redland, California, and Feature Analyst ${ }^{\circledR}$ (ArcGIS extension) 4.1 from Visual Learning Systems, Inc of Missoula, Montana. These tools were largely chosen for cost considerations. Other software for analysis or feature extraction may be suitable as well.

Four images were used in this project, all of them in SID format, each one compressed from multiple, original TIFF images. The 1997 images (1-ft resolution) were taken in September, and the 2007 images (15-cm resolution) were taken in June. All imagery was taken in 24-bit natural color.

Most features were compiled with Feature Analyst ${ }^{\circledR}$. Training polygons were selected for each image processed. It was essential to obtain training polygons over the entire image area for each feature type being compiled. However, where there were substantial differences in appearance between areas in the same category, the software performed much better by treating these different areas as belonging to separate categories and then merging them in ArcGIS afterward. During the manual clean up phase of digitizing, we found that the TIFF files provided better performance for panning and zooming than the SID files.

Processing time for Feature Analyst ${ }^{\circledR}$ generally ranged from 1 to 4 hours. However, the English Camp 2007 image took an unusually long time to process: 36 hours. Visual Learning Systems, Inc. ran the image through the same process for us to try to determine the cause, but found it ran in only 4 hours. We have not yet discovered the cause for this anomaly.

\section{Conclusions}

Prairie edges and many other land-cover categories can be efficiently compiled using automated feature extraction software, such as Feature Analyst ${ }^{\circledR}$. However, we also determined that compiling detailed information, such as grass types or even shrub/grass delineations, from imagery is not practical. The image resolution required for those applications would be so high that the cost for obtaining the imagery probably would exceed the cost of mapping the same information on the ground with a high precision GPS unit.

Lidar-derived surface data may be of use in future studies. These data would help, for example, in distinguishing between trees and shrubs based on canopy height. However, unless costs for compiling Lidar data are significantly reduced, it will remain prohibitively expensive to obtain updated surface information for change detection analyses.

To reduce future costs, we suggest subsequent prairie monitoring be tested using lower resolution imagery, perhaps $1-\mathrm{m}$ or $0.5-\mathrm{m}$ images from the National Agriculture Imagery Program (NAIP). This may provide two other benefits: (1) processing time might be significantly reduced with the smaller file sizes; and (2) the problems related to "tree lean" may be minimized, because this imagery is flown at a much higher altitude. 
Publishing support provided by the U.S. Geological Survey Publishing Network, Tacoma Publishing Service Center

For more information concerning the research in this report, contact the Director, Forest and Rangeland Ecosystem Science Center, U.S. Geological Survey, 777 NW 9th Street

Corvallis, Oregon 97330

http://fresc.usgs.gov 


\section{$\mathbb{1}$ 氙}

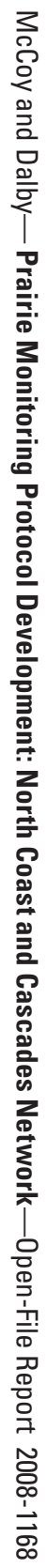

